\title{
Effective colonoscopy training techniques: strategies to improve patient outcomes
}

REVIEW

This article was published in the following Dove Press journal:

Advances in Medical Education and Practice

29 March 2016

Number of times this article has been viewed

Ioannis S Papanikolaou'

Pantelis S Karatzas ${ }^{2}$

Lazaros T Varytimiadis ${ }^{2}$

Athanasios Tsigaridas ${ }^{2}$

Michail Galanopoulos ${ }^{2}$

Nikos Viazis²

Dimitrios G Karamanolis ${ }^{2}$

'Hepato-gastroenterology Unit, 2nd Department of Internal Medicine, Attikon University General Hospital, University of Athens,

${ }^{2}$ Gastroenterology Department,

Evangelismos Hospital, Athens, Greece

Correspondence: Pantelis S Karatzas

Gastroenterology Department, Evangelismos Hospital, 45-47Ypsilantou street, PS 10676, Athens, Greece

Tel+30697772028I

Email pkaratzas@hotmail.com
Abstract: Colonoscopy has substantially evolved during the last 20 years and many different training techniques have been developed in order to improve the performance of endoscopists. The most known are mechanical simulators, virtual reality simulators, computer-simulating endoscopy, magnetic endoscopic imaging, and composite and explanted animal organ simulators. Current literature generally indicates that the use of simulators improves performance of endoscopists and enhances safety of patients, especially during the initial phase of training. Moreover, newer endoscopes and imaging techniques such as high-definition colonoscopes, chromocolonoscopy with dyes spraying, and third-eye retroscope have been incorporated in everyday practice, offering better visualization of the colon and detection of polyps. Despite the abundance of these different technological features, training devices are not widely used and no official guideline or specified training algorithm or technique for lower gastrointestinal endoscopy has been evolved. In this review, we present the most important training methods currently available and evaluate these using existing literature. We also try to propose a training algorithm for novice endoscopists.

Keywords: endoscopy, colonoscopy, teaching techniques, simulator, endoscopists, colon, polyps

\section{Introduction}

The most important indications for endoscopic examination of the colon include evaluation of abnormalities observed on contrast examination or other imaging tests, investigation of gastrointestinal (GI) bleeding, iron deficiency anemia, diarrhea of unknown origin, surveillance of patients with inflammatory bowel disease, and colorectal cancer (CRC) prevention. ${ }^{1} \mathrm{CRC}$ is the third most common cause of cancer-related death. The annual incidence of CRC in the USA is 137,000 per year and mortality exceeds 50,000 per year. $^{2}$ It is also well established that CRC develops according to the adenoma-carcinoma sequence. ${ }^{3,4}$ Thus, early detection and removal of adenomatous polyps reduces the possibility of CRC emergence. Colonoscopy is the current gold standard examination for colon polyp detection and CRC prevention. However, despite its undeniable efficiency, colonoscopy is still not optimal as some adenomatous polyps and even advanced neoplasms may be missed (miss rates are estimated to range approximately between $20 \%$ and $25 \%) .^{5-8}$ The main etiologic factors for this failure are presence of flat or diminutive adenomas, especially ones in the right-sided colon, ${ }^{9,10}$ poor bowel preparation, ${ }^{11}$ difficulty to visualize polyps at the proximal side of folds and curves of flexures during the withdrawal of colonoscope, ${ }^{8,12}$ and also the inexperience of the endoscopist. All the above, but mainly the latter, emphasize the 
need for more qualified endoscopists worldwide in order to meet the growing demand of high-quality lower GI endoscopy. In order to disseminate the knowledge and expertise on colonoscopy, not only cognitive skills are needed, but also technical excellence in order to combine patient safety with ideal adenoma detection rate (ADR).

Colonoscopy instruction has largely followed the apprenticeship model of "see one, do one, teach one". Its obvious limitations include time management and potential trauma to the patients involved. Furthermore, the apprenticeship model has promoted a trial-and-error culture of skills acquisition with little time for self-reflection or provision of formative feedback. Consequently, the apprenticeship model has been associated with significant frustration for the trainees and teachers. Colonoscopy instructors have recognized the limitations of an apprenticeship-based model, and are searching for novel methods to facilitate trainee-based endoscopic skills. Over recent years, however, the ongoing need for patient safety has emerged the issue of simulation-based training to the surface.

The goal of this review was to summarize the available training methods and new endoscopic devices that advance polyp/adenoma detection and to present possible benefits from their use.

\section{Simulators and animal models}

It should be noted that there are two main different ways to perform a colonoscopy. The first one is the one-person colonoscopy; either seated or upright, where one person uses both the control body with the remote switches (suction and air/water infusion button) and the insertion tube of the endoscope. The second one is the two-person colonoscopy, where one person handles the control body with the remote switches and the other person pushes and shafts the insertion tube of the endoscope. The two-person method carries higher risk for perforation, needs more space, and is more grueling for the endoscopists, whereas the one-person technique, especially the sitting method, carries a lower fatigue level and a significantly lower risk of perforation. ${ }^{13}$

Available training methods in endoscopy include simulators, animal models, and computerized or virtual reality (VR) devices. Of course in cases where none of the aforementioned potentials is available, the training of the new endoscopist takes place directly on real patients.

\section{Mechanical simulators}

The original endoscopic mechanical simulators were based on plastic. The widely known Erlangen plastic mannequin described in 1974 offered the possibility to perform gastroscopy using a flexible endoscope. Despite improvements, which could be attributed to its implementation, mechanical models in general lack realism due to poor simulation of tissue properties. Medical and technological evolution allowed the use of better simulators, such as animal models or combined mechanical and explanted organ models. Nevertheless, pure mechanical simulators offer a great learning technique to the novice endoscopist. There is a physical model made by polyvinyl chloride and a virtual simulator for training of colonoscopic insertion. Various techniques including a method to apply pressure to the abdomen and consideration for patient's pain can be trained using these models. ${ }^{14}$

\section{Computerized or VR devices}

Simulation based on computers was first described 30 years ago and lacked realism. Fortunately, the advancements in technology led to more user-friendly and realistic simulators. ${ }^{15,16}$ The available technologies include interactive video technology, computer graphics technology, and videographic tool technology. In the first one, previously saved real-life endoscopic images were displayed in response to the movements of the endoscopist. In the second one, computerized images were used in response to the movement of the endoscope. Finally, in the videographic tool technology, real-time insertion of virtual endoscopic devices was based on real-life endoscopic images. ${ }^{17}$

\section{Computer simulating endoscopy}

Initiation of endoscopy simulation based on computers took place in the late $60 \mathrm{~s} .{ }^{17}$ Important developments in the field led to upgraded simulators, which offer the possibility to train all endoscopic ways of examination, such as endoscopic ultrasound (EUS), endoscopic retrograde cholangiopancreatography (ERCP), colonoscopy, and esophagogastroduodenoscopy (EGD). Training with such simulators mainly enhances the ability to navigate the scope and correct possible loops, but lacks realism in performing invasive procedures. ${ }^{19-21}$ The most successful and widely used simulators are the following:

1. The Simbionix Simulator GI Mentor II (GIM; Cleveland, $\mathrm{OH}, \mathrm{USA}$ ): EGD, EUS, ERCP, colonoscopy, and sigmoidoscopy can all be simulated with the GIM. Different endoscopic cases, ranging from simple endoscopic cases to advanced endoscopic skills, such as hemostasis of upper GI bleeding are offered. The simulator archives all data related to the procedures, which can later be used in order to estimate the improvement of each trainee. GIM can also simulate patient's pain and loop formation. 
2. The Olympus colonoscopy simulator Endo TS-1 (ETS1; Olympus Keymed, UK): The ETS1 is a new VR simulator that simulates in real-time insertion of the scope. ${ }^{22}$ ETS1 is based on an Olympus CF180L colonoscope offering simulation of the most common endoscopic scenarios, such as shaft looping, tip contact, variable shaft stiffness, application of abdominal pressure, and movement of the patient. Moreover, there is the potentiality to watch the positioning of the endoscope through a simulator of a three-dimensional endoscope image viewer. The novice endoscopist can be trained on inserting and withdrawing the colonoscope, finding a lesion, and hopefully in the following years evolved software will offer a simulation of intervening scenarios, such a polypectomy. ${ }^{23}$

3. AccuTouch endoscopy simulator CAE Healthcare (Canada): Training on EGD, colonoscopy, and ERCP are offered with this simulator as well as performing polypectomy, hemostasis, and tissue sampling.

4. Koken Co. Ltd., Tokyo, Japan: The LM-107 simulator type II is a training model for practicing colonoscopy and insertion into the small intestine using a balloon enteroscope. Furthermore, it allows training in endoscopic interventions, such as resecting a polyp and stopping bleeding. The simulator was based on special silicone rubber that resembles living body in the observation field. Observation can be performed by attaching a simulated polyp in the ascending and descending colon. Training in insertion of the device into the small intestine and shortening technique can be accomplished using double-balloon and single-balloon endoscopes.

5. Kyoto Kagaku Co., Ltd., Kitanekoya-cho Fushimi-ku Kyoto, Japan: This simulator is made of a soft, flexible, and airtight element, which offers apart from the standard ability to insert and withdraw the endoscope, the potential to insufflate and suck air, as well as to train on demanding maneuver techniques. The Kyoto Kagaku simulator offers a realistic simulation, helping the novice endoscopist to learn how to avoid creating "loops" and how to straighten them in a safe manner. The training body may be rotated to all possible positions like the patient's body in real-life endoscopy. Moreover, the trainee can put pressure in the abdominal wall by using the supplied skin cover.

\section{Magnetic endoscopic imaging (Scope Guide)}

Magnetic endoscopic imaging (MEI) introduced a relatively modern method for easing endoscopy training. This procedure uses real-time data concerning the three-dimensional positioning of the endoscope, which is really beneficial for the amateur endoscopist so as to recognize loop formation. Real-time MEI uses three generator coils positioned below the patient. Each magnetic pulse is detected by a series of sensor (receiver) coils positioned $12 \mathrm{~cm}$ apart, along a catheter that is inserted through the biopsy channel of the endoscope. From the electrical signal induced in each sensor coil, the precise three-dimensional position and orientation of each sensor coil can be calculated. A smooth curve is fitted through each of the calculated points, generating a real-time, three-dimensional graphic image of the colonoscope shaft. It is generally believed that MEI offers important information to the endoscopist, especially regarding loop formation. ${ }^{24,25}$ MEI has shown really favorable results on easing colonoscopy completion, ${ }^{26-28}$ locating lesions, ${ }^{29,30}$ patient comfort, ${ }^{28,31}$ and rating colonoscopy competence. ${ }^{32}$

\section{Ex vivo animal models}

Ex vivo animal tissue models offer another approach to VR. Studies on bovine models mention the realism of using animal models despite differences in anatomy and tissue texture. Intubation times on animal models and actual patient-based colonoscopy data are well related, pointing out the usefulness of these models. ${ }^{33}$ Animal models offer the best endoscopic alternative, but ethical concerns limit their use.

\section{Composite and explanted animal organ simulators}

Composite simulators combine plastic parts and explanted animal organs, in an effort to improve the training technique. These devices were simulating many endoscopic situations and gave the possibility to perform a number of procedures: gastroscopy, colonoscopy, hemostasis, endoscopic mucosal resection (EMR), polypectomy, ERCP, percutaneous endoscopic gastrostomy tube insertion, EUS, and double-balloon enteroscopy. ${ }^{34,35}$ The main advantages of ex vivo animal models are a more realistic feel compared with purely mechanical models, the ability to practice endoscopy in a controlled setting, and the cost-effectiveness compared with computer-based simulators. On the other hand, the time needed to prepare the animal model, the need to dispose the tissue, and the different structure of tissue are the main disadvantages. ${ }^{17}$

\section{Comparative studies and efficacy}

Two types of simulator studies exist: validity studies and clinical trials. Construct validity reflects the ability of a simulation device to discriminate endoscopy experience of the user by 
calculating parameters such as procedure time, colonic extent examined, and detection of lesions. Validity studies evaluate initially a simulator, but clinical trials are those to prove the benefit of using an endoscopic simulator in the clinical setting. Apart from a pilot study, which validates an ERCP mechanical simulator that is not commercially available, ${ }^{36}$ there is no other published validity or clinical (outcome) study on mechanical simulators. Such studies were conducted for ex vivo animal simulators and computer simulators.

Regarding colonoscopy assisted by computer simulators, there is an abundance of validation studies. The main questions that needed to be answered in the majority of these studies were whether the use of a simulator improves training of endoscopists, when and how is the best way to use simulators, if simulators improve complication rates, and if simulators could be used to discern the experience of an endoscopist.

\section{The role of simulators in the initial phase of training}

Two studies ${ }^{37,38}$ have shown a clear benefit in the early phase of training, potentially leading to a shorter learning curve and better performance in the endoscopy room. Interactive animated graphics explaining particular endoscope loops and variations of colonic anatomy that are typically encountered are the main factors that improve the teaching procedure during the early phase of hands-on training. Simulation should spare patients from being used for the early phases of training and should speed up and quantify the learning process.

There is also a randomized, controlled, blinded, multicenter trial from the USA, ${ }^{39}$ during which 45 GI fellows were randomized to either 10 hours of training on a simulator during their first 2 months of fellowship or to no training at all. The evaluation of their performance on 200 subsequent patient colonoscopies was the endpoint of this study. The simulator-trained group showed significantly better competence during the first 80 procedures, but the number of endoscopies (mean 160) needed to achieve $90 \%$ competence was almost equal for the two groups.

Another multinational, multicenter, single-blind, randomized, controlled trial included 36 novice endoscopists who were randomized to 16 hours of simulator training (subjects) or patient-based training (controls). The endoscopists performed three simulator procedures before and after training. Three cases were assessed after training by blinded experts. Performance was significantly improved on simulated cases compared with patient-based training. Subjects had higher completion rates $(P=0.001)$, shorter completion times
$(P<0.001)$, and demonstrated higher technical skills, such as reduced pain scores, limited use of abdominal pressure, and loop management. ${ }^{40}$

A randomized, controlled trial ${ }^{41}$ compared two groups; one included novice GI fellows who underwent a 6-hour simulator training and the other was a control group. The results showed that the first group performed better in all parameters apart from cecal intubation time (CIT). Though, it must be noted that the better performance was equalized for both groups after the first 30 procedures.

Another study of eight surgical residents claimed that examination efficiency was improved by offering a monthly simulation training during 2 years compared with the standard training without simulator. ${ }^{42}$ A study from the $\mathrm{USA}^{43}$ proved that VR simulator training accelerates development of the hand-eye skills for adequate sigmoidoscopy.

\section{Effect of type of training and feedback}

Intensification of training programs also plays an important role according to a study from St Marks Hospital. ${ }^{44}$ This was the first prospective study to claim a positive, sustained impact of intensive hands-on colonoscopy training course. Twenty-one trainee endoscopists with varying experience on lower GI endoscopy underwent an accelerated colonoscopy training week, during which performance in key areas of skill acquisition was measured. Endoscopists improved in most of colonoscopy technique parameters after 5 days of intensive (one-to-one) training. This result was the same at mediumterm follow-up, whereas trainees improved their technique with concomitant decrease in procedure time. Nevertheless, these results correspond to a significant reduction in CIT whereas exertion time remains to be further validated.

Simulators are not enough for proper training of novice endoscopists and feedback from experienced endoscopists is mandatory. That is claimed by an interesting study, where 22 novel gastroenterology trainees were randomized to a group, which received special training, provided by an experienced supervisor and a controlled group, which received no feedback during its training. Although both groups had the ability to complete the procedure on the simulator, the feedback group performed better (faster CIT, higher percentage of mucosa visualized) with less perforations (zero in the feedback group vs seven in the no-feedback group). ${ }^{45}$ The importance of feedback was also stated in an English study, ${ }^{46}$ where trainees using simulator demonstrated no improvement without feedback from an expert.

There are two interesting studies which confirm that better technical skills acquired with simulators are also transferred 
to real-life colonoscopy. The first one was conducted using the ETS1 computer simulator. Thirty-six trainees without previous endoscopy experience were randomized either to 16 hours simulation or to standard patient-based training. Performing three test colonoscopies on the simulator and three live colonoscopies and being evaluated by blinded experts was the primary endpoint. Higher cecal intubation rates and better technical skills were recorded for those trained with the simulator. The simulator group did not perform colonoscopies on real patients during training, but on real-patient test cases the performance was equal, showing that simulator skills were transferred to real-life endoscopy. ${ }^{40}$ The second study compares a human-based and a computer-based technical skills assessment tool in live and simulated GI endoscopies performed by consultants and trainees. Two hundred and ten live and simulated endoscopies were performed by 18 consultants and 37 trainees. The construct validity and mean interrater reliability were statistically better for the human-based tool. ${ }^{26}$ Residents trained on a colonoscopy simulator prior to their first patient-based colonoscopy performed significantly better in the clinical setting than controls, suggesting that skills were transferred to real patients. ${ }^{47}$

A randomized trial of independent (automated simulator feedback only) versus proctored (human expert feedback plus simulator feedback) simulator training included medical students who were able to perform a standardized VR colonoscopy case at three different time points. The first one was performed before the initiation of training, the second one after the completion of training (posttraining), and the third one after a median of 4.5 months without practice (retention). Student's performance was evaluated by proficient criteria and compared for the two groups. Thirteen trainees (eight proctored and five independent) participated in the trial. Proctored and independent groups performed equally. The results revealed improvement from baseline to post-training endoscopy, which was retained in the retention testing. Therefore, it was concluded that colonoscopy skills could be retained for several months after proficiency-based VR simulator training, regardless of the training approach (proctored or independent) used..$^{48}$

Regarding patient comfort, there is a reference ${ }^{41}$ that patients report less discomfort when colonoscopy is performed by simulator-trained endoscopists, reflecting a direct benefit to the patient by using computer-based endoscopy simulator training.

It must be noticed that there is only one prospective randomized trial that casts doubts on the value of VR-based endoscopy simulation. This study regarded medical residents who were trained in sigmoidoscopy and the results showed no improvement for those who underwent simulator-based training in comparison to those who did not. ${ }^{49}$

\section{Magnetic endoscopic imaging}

Regarding MEI, there is one study that evaluates the usefulness of the device..$^{50}$ Only one novice trainee took part in the study, with previous experience of only 15 colonoscopies. The aim of the study was the management of looping and the learning of the maneuvers required to straighten the colonoscope shaft. The investigators recorded looping duration and the number of attempts that were needed to straighten the colonoscope shaft and advance the instrument tip. Primary measured endpoints were intubation time, duration of looping, and the total attempts to straighten the scope per procedure. The time that colonoscope was looping and mean intubation time were shorter when the trainee used MEI view. The study suggested that use of MEI improved loop reduction techniques and shortened learning curve. The effect of MEI on the performance of novice endoscopists and the total load of work in colonoscopy were tested in the following study $^{51}$ : 20 novice endoscopists underwent a teaching course and subsequently performed two colonoscopies on a model. The first group used MEI, while the second did not. Second lower GI endoscopy was performed with the imager for the second group and without it for the first group. Participants who initially used MEI demonstrated a significant improvement in their performance. Total workload was similar for both groups.

\section{Discrimination studies}

The AccuTouch flexible sigmoidoscopy simulator has the ability to discriminate novice and expert endoscopists according to two studies. ${ }^{52,53}$ As expected, experts outperformed residents, but this difference was not sustained between senior residents and experts. It must be noted though that following studies could not prove any advantage for endoscopists trained on simulators when compared with endoscopists trained directly on real patients. ${ }^{41,49}$ Gerson and Van Dam ${ }^{49}$ conducted a study with nine residents (group 1 - simulatortrained group) and seven residents (group 2 - traditional bedside teaching group), who performed and completed 66 sigmoidoscopic examinations. The initial endoscope insertion and the negotiation of the rectosigmoid junction was more difficult for participants in group 1 (mean score \pm standard error of mean 2.9 \pm 0.2$)$ than those in group $2(3.8 \pm 0.2)$ $(P<0.001)$. Ten of 34 examinations $(29 \%)$ in group 1 reached independently the splenic flexure compared with 23 out of 32 
examinations $(72 \%)$ in group $2(P=0.001)$. Retroflexion was successfully performed by 19 out of 34 (56\%) in group 1 compared with 27 out of $32(84 \%)$ in group $2(P=0.02)$. There was no statistical difference between the two groups concerning the average procedure time, the patient satisfaction, and discomfort associated with the procedure.

\section{The dissent}

In discordance to the aforementioned bibliography, there is a prospective, observational trial, ${ }^{54}$ which concludes that simulator does not offer a realistic simulation of human endoscopy. Five gastroenterology fellows on their first year of training and six gastroenterology attendings from a single academic center performed six common endoscopic cases on the Simbionix GIM endoscopy simulator. The simulator measured 13 performance parameters, which were compared between the two study groups. All participants completed a survey evaluating the realism of the simulator. No significant overall differences were found between novices and experts, as both groups were able to complete the tasks in the simulated cases. On the contrary, level of expertise was discriminated by the simulator based on parameters related to the time spent for the procedure (total time, time to reach the second duodenum, time to reach the cecum, and efficiency of screening).

\section{Polyp detection and new endoscopic devices}

During the last decade, a great variety of new technologies and techniques have emerged for detection and characterization of colon lesions. The high-definition colonoscope showed that the variance in ADR between high-definition colonoscopy and standard-definition colonoscopy was only $3.5 \% .{ }^{55}$ The wide-angle colonoscope with 170 degrees of forward-viewing angle visualizes more mucosa than a standard colonoscope with a 140-degree viewing angle. The only benefit though is its association with shorter withdrawal time. Low ADR results have also emerged by using cap-assisted colonoscope, which flattens colonic folds and colon capsule endoscope, although the latter one is recommended by the European Society of GI Endoscopy as an alternative examination to colonoscopy in non-high-risk individuals for CRC. ${ }^{56}$ Apart from these, a technique that is commonly used is the retroflexion in order to visualize the dentate line in the rectum mainly and the proximal colon secondary. Studies have not shown any ADR improvement and the complications, such as perforation, lead to the opinion of a nonrecommended examination, especially for trainees and less experienced endoscopists. ${ }^{57}$
A new era in discovering and characterization of diminutive polyps and flat lesions has come with the chromocolonoscopy with dyes spraying such as indigo carmine, which improves the visual antithesis between normal and pathologic mucosa. The time consumption though, needed for dye spraying, has led to the proposal that this procedure should rather be reserved for high-risk patients for dysplasia, ${ }^{58}$ using the method of dying the entire colon during colonoscope withdrawal, so as to increase the ADR. Consequently, due to the need for saving time, virtual chromoendoscopy has emerged, using optical and/or electronic methods (instead of old ones dyes, catheters, etc), such as narrow band imaging (NBI), Fuji intelligent color enhancement, and autofluorescence imaging. Virtual chromoendoscopy uses different wavelengths, which infiltrate tissues to different layers. Blue light is diffused more superficially than red light. ${ }^{59}$ Studies have proven that NBI-high magnification is the most accurate technique for differentiating diminutive colorectal polyps even for inexperienced endoscopists who undergo a 1-hour lesson organized by an experienced endoscopist. ${ }^{60}$ This outcome was verified for the high endoscopy experience group as well, showing that NBI-high is accurate enough to provide a high level of reproducible agreement in differentiating dysplastic from nondysplastic colorectal polyps. Furthermore, it is well established now that diminutive polyps sometimes harbor dysplastic characteristics leading to their resection and submission for pathology evaluation. If this strategy is replaced by the "characterize, resect, and discard" strategy then the cost saving would be enormous. ${ }^{61-63}$ In skilled hands, precision rates for a "resect-and-discard" policy are higher for NBI, ${ }^{6466}$ Fuji intelligent color enhancement, ${ }^{67,68}$ and autofluorescence imaging, ${ }^{69}$ ranging between $85 \%$ and $92 \%$, but these rates were reported to be lower when used by nonexperienced examiners. . $^{64,70,71}$

Despite the initial enthusiasm, even pancolonic virtual chromoendoscopy has some disadvantages including the difficulty of localization of diminutive and flat lesions and the reduced ADR and polyp detection rate (PDR). Technical reasons such as the excessive brightness of the virtual image and the inability for an ideal preparation of the colon are implicated as the drawbacks of virtual chromoendoscopy. These factors might lead to the misinterpretation of bile fluid and stool residues as pathological lesions. ${ }^{72}$

Newer teaching tools should be developed to train less experienced endoscopists to obtain an acceptable level of accuracy and confidence in real-time colonoscopy procedures. Although there are advantages to interactive didactic teaching, newer techniques such as computer-based or web-based 
teaching tools show an easier accessibility to endoscopists who can review and assimilate them at their own convenience. An important aspect of training is testing the performance after training to evaluate the level of competence achieved. Studies have shown that video clips closely simulate live colonoscopy in comparison with images teaching strategy, which have narrowed real-time assessment in clinical practice so far. ${ }^{73}$

Apart from these well-established visualization techniques, new methods are evolving that have initially shown encouraging outcomes. Third-eye retroscope is a device that is launched through the colonoscope channel and can retroflex 180 degrees, providing a 135-degree view behind colonic folds. Although this has been shown to increase ADR by $23 \%$, there are some limitations in its use, such as the reduced suctioning capacity and the need of device removal when biopsy forceps or a polypectomy snare is needed. ${ }^{73}$ The full-spectrum endoscope is designed with one front and two lateral cameras combined with light emitting diode groups, offering a 330-degree image of the lumen. It has shown promising results in terms of ADR and PDR improvement for colonoscopy, but additional research will probably be required before definitive conclusions can be drawn. ${ }^{73}$ Another innovation that should be mentioned is infusing water instead of or in addition to air during colonoscopy. ${ }^{74,75}$ Infusion of water dilates the colon and can be performed either in addition to insufflating air (water-immersion method) or without insufflating air (water-exchange method). ${ }^{76,77}$ Although this procedure was initially designed to ease cecal approach, it is now perceived that it might increase ADR.

\section{Polyp removal and related training methods}

As already mentioned, progress in colonoscopy techniques has improved the detection of colorectal polyps. Following polyp detection, the endoscopist must decide which is the ideal way to remove it. Offered techniques range from cold or hot forceps polypectomy, cold snare polypectomy, hot snare polypectomy, EMR, and endoscopic submucosal dissection (ESD). For less experienced endoscopists, various training methods such as physical models, virtual simulators and animal models, and clinical stepwise practice are used to increase the learning curves of such endoscopic techniques.

Regarding simple polypectomy, the Welsh Institute for Minimal Access Therapy ${ }^{78}$ has designed a porcine model. Goal of the study was to prove that polypectomy in an ex vivo porcine intestine can be realistic and can also improve the acquisition of complex polypectomy skills within a safe and controlled environment.
EMR is mainly used for intramucosal neoplasia or very large polyps, especially those ranging between 15 and $20 \mathrm{~mm}$ with en bloc method or for those over $20 \mathrm{~mm}$ with piecemeal EMR. Normally, training of EMR first includes observing expert's technique, then performing easy cases such as small rectal polyps under supervision, and finally, treating difficult lesions in the entire colon. In clinical practice, the use of $0.13 \%$ hyaluronic acid in EMR, which maintains the mucosal elevation longer than saline, is recommended for less experienced endoscopists. ${ }^{79-81}$ In Japan, harvested animal models have recently been used for training of EMR ${ }^{14}$ It should be highlighted that there are no virtual simulators for training of EMR, whereas polypectomy of pedunculated polyps can be practiced with virtual simulators.

Finally, ESD is a new technique for the resection of early T1a intramucosal neoplasias, mainly in the stomach. Although it is associated with lower recurrence rates, the technique carries higher perforation rates and is more timeconsuming than alternative methods, including EMR. ${ }^{82}$ Colorectal ESD training is usually a stepwise system, starting with observing and helping in ESD performed by highly experienced endoscopists. ${ }^{83-85}$ The next step is training on animal models. Porcine and canine in vivo models have showed promising training results. ${ }^{86,87}$ However, they are expensive, inconvenient, and require the animal being sacrificed. In contrast, ex vivo animal models are inexpensive and the recent development of simulated blood flow enabled more practical training including endoscopic hemostasis. ${ }^{83}$ The suggested number of ESDs during the training period is 30, as suggested by the European Society of GI Endoscopy. Nevertheless there is improvement in the technical skills of the endoscopist after the first 10-15 ESD cases have been performed. ${ }^{83}$ Finally, clinical practice is performed under the supervision of experts, beginning with gastric ESD (20-40 procedures to gain proficiency), then rectal ESD, and finally colonic ESD. ${ }^{88,89}$ It should be mentioned that there are no virtual simulators for training of ESD, something that is strongly desired.

\section{Conclusion}

GI endoscopy is one of the most developing invasive techniques in the medical evolution, offering to both doctors and patients the advantage of preventing or even resecting common neoplasias. Given the abundance of different and complicated procedures of GI endoscopy, a constantly better, more efficacious, and intensive training is needed. This is now possible due to various simulators and animal models, providing a safe way for novice endoscopists to famil- 
iarize with the endoscopic devices and procedures without causing discomfort or even harm to the patients. Moreover, in the field of adenoma and intramucosal neoplasia detection, there is a revolution of endoscopic technological advancements in the fields of imaging and/or accessories, which could allow even beginners to detect "suspicious" mucosal lesions and effectively remove them. Most of these modern training adjuncts, however, are scourged by high costs and therefore are not available in every endoscopy unit throughout the world. Therefore, in many cases, their use, although desirable, has to be forfeited. In these cases, training can still be obtained beginning from a combination of lectures, reading materials, and possibly tests that trainees should first pass, before they advance into careful hands-on examination of patients under close supervision by experienced trainers. ${ }^{13}$ These examinations should be performed in a stepwise fashion, beginning from diagnostic procedures and then advancing to interventional ones. Although use of simulators and other technological advancements is, of course, the preferred pathway, the other alternative can also be followed in cases where there is no availability of these more advanced means. The common prerequisite in both these strategies is the presence of experienced, competent, and devoted trainers, who can solve questions, give solutions to problems that might arise during implementation of these training methods and/or procedures, but - most important - who can guide trainees through their initial steps in colonoscopy and help achieve the best outcomes for the benefit of patients.

\section{Disclosure}

The authors report no conflicts of interest in this work.

\section{References}

1. Appropriate use of gastrointestinal endoscopy. American Society for Gastrointestinal Endoscopy. Gastrointest Endosc. 2000;52(6):831-837.

2. Saito H. Screening for colorectal cancer: current status in Japan. Dis Colon Rectum. 2000;43(10 Suppl):S78-S84.

3. Zauber AG, Winawer SJ, O'Brien MJ, et al. Colonoscopic polypectomy and long-term prevention of colorectal-cancer deaths. $N$ Engl J Med. 2012;366(8):687-696.

4. Jacob BJ, Moineddin R, Sutradhar R, Baxter NN, Urbach DR. Effect of colonoscopy on colorectal cancer incidence and mortality: an instrumental variable analysis. Gastrointest Endosc. 2012;76(2):355.e1-364.e1.

5. Hixson LJ, Fennerty MB, Sampliner RE, McGee D, Garewal H. Prospective study of the frequency and size distribution of polyps missed by colonoscopy. J Natl Cancer Inst. 1990;82(22):1769-1772.

6. Rex DK, Cutler CS, Lemmel GT, et al. Colonoscopic miss rates of adenomas determined by back-to-back colonoscopies. Gastroenterology. 1997;112(1):24-28.

7. van Rijn JC, Reitsma JB, Stoker J, Bossuyt PM, van Deventer SJ, Dekker E. Polyp miss rate determined by tandem colonoscopy: a systematic review. Am J Gastroenterol. 2006;101(2):343-350.
8. Robertson DJ. Colonoscopy for colorectal cancer prevention: is it fulfilling the promise? Gastrointest Endosc. 2010;71(1):118-120.

9. Chen SC, Rex DK. Endoscopist can be more powerful than age and male gender in predicting adenoma detection at colonoscopy. Am J Gastroenterol. 2007;102(4):856-861.

10. Lee RH, Tang RS, Muthusamy VR, et al. Quality of colonoscopy withdrawal technique and variability in adenoma detection rates (with videos). Gastrointest Endosc. 2011;74(1):128-134.

11. Barclay RL, Vicari JJ, Doughty AS, Johanson JF, Greenlaw RL. Colonoscopic withdrawal times and adenoma detection during screening colonoscopy. N Engl J Med. 2006;355(24):2533-2541.

12. Kaminski MF, Regula J, Kraszewska E, et al. Quality indicators for colonoscopy and the risk of interval cancer. $N$ Engl J Med. 2010;362(19):1795-1803.

13. Lee SH, Park YK, Lee DJ, Kim KM. Colonoscopy procedural skills and training for new beginners. World J Gastroenterol. 2014; 20(45):16984-16995.

14. Yoshida N, Fernandopulle N, Inada Y, Naito Y, Itoh Y. Training methods and models for colonoscopic insertion, endoscopic mucosal resection, and endoscopic submucosal dissection. Dig Dis Sci. 2014;59(9):2081-2090.

15. Williams CB, Baillie J, Gillies DF, Borislow D, Cotton PB. Teaching gastrointestinal endoscopy by computer simulation: a prototype for colonoscopy and ERCP. Gastrointest Endosc. 1990;36(1):49-54.

16. Noar MD. Robotics interactive endoscopy simulation of ERCP/sphincterotomy and EGD. Endoscopy. 1992;24(Suppl 2):539-541.

17. Desilets DJ, Banerjee S, Barth BA, et al. Endoscopic simulators. Gastrointest Endosc. 2011;73(5):861-867.

18. Triantafyllou K, Lazaridis LD, Dimitriadis GD. Virtual reality simulators for gastrointestinal endoscopy training. World J Gastrointest Endosc. 2014;6(1):6-12.

19. Hill A, Horswill MS, Plooy AM, et al. Assessing the realism of colonoscopy simulation: the development of an instrument and systematic comparison of 4 simulators. Gastrointest Endosc. 2012;75(3):631-640.

20. Duthie GS, Drew PJ, Hughes MA, et al. A UK training programme for nurse practitioner flexible sigmoidoscopy and a prospective evaluation of the practice of the first UK trained nurse flexible sigmoidoscopist. Gut. 1998;43(5):711-714.

21. Mahmood T, Darzi A. A study to validate the colonoscopy simulator. Surg Endosc. 2003;17(10):1583-1589.

22. Williams CB, Thomas-Gibson S. Rational colonoscopy, realistic simulation, and accelerated teaching. Gastrointest Endosc Clin N Am. 2006;16(3):457-470.

23. Haycock AV, Bassett P, Bladen J, Thomas-Gibson S. Validation of the second-generation Olympus colonoscopy simulator for skills assessment. Endoscopy. 2009;41(11):952-958.

24. Shah SG, Brooker JC, Williams CB, Thapar C, Saunders BP. Effect of magnetic endoscope imaging on colonoscopy performance: a randomised controlled trial. Lancet. 2000;356(9243):1718-1722.

25. Shah SG, Brooker JC, Thapar C, Suzuki N, Williams CB, Saunders BP. Effect of magnetic endoscope imaging on patient tolerance and sedation requirements during colonoscopy: a randomized controlled trial. Gastrointest Endosc. 2002;55(7):832-837.

26. Shah SG, Brooker JC, Williams CB, Thapar C, Suzuki N, Saunders BP. The variable stiffness colonoscope: assessment of efficacy by magnetic endoscope imaging. Gastrointest Endosc. 2002;56(2): 195-201.

27. Hoff G, Bretthauer M, Dahler S, et al. Improvement in caecal intubation rate and pain reduction by using 3-dimensional magnetic imaging for unsedated colonoscopy: a randomized trial of patients referred for colonoscopy. Scand J Gastroenterol. 2007;42(7):885-889.

28. Jess $\mathrm{P}$, Bulut $\mathrm{O}$, Almasi A, Waaddegaard $\mathrm{P}$. The usefulness of a magnetic endoscope locating device in colonoscopy in daily practice: a prospective case-controlled study. Surg Endosc. 2009;23(6):1353-1355.

29. Cheung HY, Chung CC, Kwok SY, Tsang WW, Li MK. Improvement in colonoscopy performance with adjunctive magnetic endoscope imaging: a randomized controlled trial. Endoscopy. 2006;38(3):214-217. 
30. Shah SG, Pearson HJ, Moss S, Kweka E, Jalal PK, Saunders BP. Magnetic endoscope imaging: a new technique for localizing colonic lesions. Endoscopy. 2002;34(11):900-904.

31. Shah SG, Brooker JC, Thapar C, Williams CB, Saunders BP. Patient pain during colonoscopy: an analysis using real-time magnetic endoscope imaging. Endoscopy. 2002;34(6):435-440.

32. Shah SG, Thomas-Gibson S, Brooker JC, et al. Use of video and magnetic endoscope imaging for rating competence at colonoscopy: validation of a measurement tool. Gastrointest Endosc. 2002;56(4):568-573.

33. Sedlack RE, Baron TH, Downing SM, Schwartz AJ. Validation of a colonoscopy simulation model for skills assessment. Am J Gastroenterol. 2007;102(1):64-74.

34. Neumann M, Mayer G, Ell C, et al. The Erlangen Endo-Trainer: lifelike simulation for diagnostic and interventional endoscopic retrograde cholangiography. Endoscopy. 2000;32(11):906-910.

35. May A, Nachbar L, Schneider M, Neumann M, Ell C. Push-and-pull enteroscopy using the double-balloon technique: method of assessing depth of insertion and training of the enteroscopy technique using the Erlangen Endo-Trainer. Endoscopy. 2005;37(1):66-70.

36. Leung JW, Lee JG, Rojany M, Wilson R, Leung FW. Development of a novel ERCP mechanical simulator. Gastrointest Endosc. 2007;65(7):1056-1062.

37. Cantù $P$, Penagini R. Computer simulators: the present and near future of training in digestive endoscopy. Dig Liver Dis. 2012;44(2): $106-110$.

38. Williams CB, Saunders BP, Bladen JS. Development of colonoscopy teaching simulation. Endoscopy. 2000;32(11):901-905.

39. Cohen J, Cohen SA, Vora KC, et al. Multicenter, randomized, controlled trial of virtual-reality simulator training in acquisition of competency in colonoscopy. Gastrointest Endosc. 2006;64(3):361-368.

40. Haycock A, Koch AD, Familiari P, et al. Training and transfer of colonoscopy skills: a multinational, randomized, blinded, controlled trial of simulator versus bedside training. Gastrointest Endosc. 2010;71(2):298-307.

41. Sedlack RE, Kolars JC, Alexander JA. Computer simulation training enhances patient comfort during endoscopy. Clin Gastroenterol Hepatol. 2004;2(4):348-352.

42. Clark JA, Volchok JA, Hazey JW, Sadighi PJ, Fanelli RD. Initial experience using an endoscopic simulator to train surgical residents in flexible endoscopy in a community medical center residency program. Curr Surg. 2005;62(1):59-63.

43. Tuggy ML. Virtual reality flexible sigmoidoscopy simulator training: impact on resident performance. J Am Board Fam Pract 1998;11(6):426-433.

44. Thomas-Gibson S, Bassett P, Suzuki N, Brown GJ, Williams CB, Saunders BP. Intensive training over 5 days improves colonoscopy skills long-term. Endoscopy. 2007;39(9):818-824.

45. Kruglikova I, Grantcharov TP, Drewes AM, Funch-Jensen P. The impact of constructive feedback on training in gastrointestinal endoscopy using high-fidelity virtual-reality simulation: a randomised controlled trial. Gut. 2010;59(2):181-185.

46. Mahmood T, Darzi A. The learning curve for a colonoscopy simulator in the absence of any feedback: no feedback, no learning. Surg Endosc. 2004;18(8):1224-1230.

47. Park J, MacRae H, Musselman LJ, et al. Randomized controlled trial of virtual reality simulator training: transfer to live patients. Am J Surg. 2007;194(2):205-211.

48. Snyder CW, Vandromme MJ, Tyra SL, Hawn MT. Retention of colonoscopy skills after virtual reality simulator training by independent and proctored methods. Am Surg. 2010;76(7):743-746.

49. Gerson LB, Van Dam J. A prospective randomized trial comparing a virtual reality simulator to bedside teaching for training in sigmoidoscopy. Endoscopy. 2003;35(7):569-575.

50. Shah SG, Thomas-Gibson S, Lockett M, et al. Effect of real-time magnetic endoscope imaging on the teaching and acquisition of colonoscopy skills: results from a single trainee. Endoscopy. 2003;35(5): $421-425$.
51. Coderre S, Anderson J, Rikers R, Dunckley P, Holbrook K, McLaughlin K Early use of magnetic endoscopic imaging by novice colonoscopists: improved performance without increase in workload. Can J Gastroenterol. 2010;24(12):727-732.

52. Datta V, Mandalia M, Mackay S, Darzi A. The PreOp flexible sigmoidoscopy trainer. Validation and early evaluation of a virtual reality based system. Surg Endosc. 2002;16(10):1459-1463.

53. MacDonald J, Ketchum J, Williams RG, Rogers LQ. A lay person versus a trained endoscopist: can the preop endoscopy simulator detect a difference? Surg Endosc. 2003;17(6):896-898.

54. Kim S, Spencer G, Makar GA, et al. Lack of a discriminatory function for endoscopy skills on a computer-based simulator. Surg Endosc. 2010;24(12):3008-3015.

55. Subramanian V, Mannath J, Hawkey CJ, Ragunath K. High definition colonoscopy vs. standard video endoscopy for the detection of colonic polyps: a meta-analysis. Endoscopy. 2011;43(6):499-505.

56. Spada C, Hassan C, Galmiche JP, et al. Colon capsule endoscopy: European Society of Gastrointestinal Endoscopy (ESGE) Guideline. Endoscopy. 2012;44(5):527-536.

57. Saad A, Rex DK. Routine rectal retroflexion during colonoscopy has a low yield for neoplasia. World J Gastroenterol. 2008;14(42): 6503-6505.

58. Kahi CJ, Anderson JC, Waxman I, et al. High-definition chromocolonoscopy vs. high-definition white light colonoscopy for average-risk colorectal cancer screening. Am J Gastroenterol. 2010;105(6):1301-1307.

59. Emura F, Saito Y, Ikematsu H. Narrow-band imaging optical chromocolonoscopy: advantages and limitations. World J Gastroenterol. 2008;14(31):4867-4872.

60. Higashi R, Uraoka T, Kato J, et al. Diagnostic accuracy of narrowband imaging and pit pattern analysis significantly improved for less-experienced endoscopists after an expanded training program. Gastrointest Endosc. 2010;72(1):127-135.

61. Rex DK, Kahi C, O’Brien M, et al. The American Society for Gastrointestinal Endoscopy PIVI (Preservation and Incorporation of Valuable Endoscopic Innovations) on real-time endoscopic assessment of the histology of diminutive colorectal polyps. Gastrointest Endosc. 2011;73(3):419-422.

62. Ignjatovic A, East JE, Suzuki N, Vance M, Guenther T, Saunders BP. Optical diagnosis of small colorectal polyps at routine colonoscopy (Detect InSpect ChAracterise Resect and Discard; DISCARD trial): a prospective cohort study. Lancet Oncol. 2009;10(12):1171-1178.

63. Kessler WR, Imperiale TF, Klein RW, Wielage RC, Rex DK. A quantitative assessment of the risks and cost savings of forgoing histologic examination of diminutive polyps. Endoscopy. 2011;43(8):683-691.

64. Gross S, Trautwein C, Behrens A, et al. Computer-based classification of small colorectal polyps by using narrow-band imaging with optical magnification. Gastrointest Endosc. 2011;74(6):1354-1359.

65. Gupta N, Bansal A, Rao D, et al. Accuracy of in vivo optical diagnosis of colon polyp histology by narrow-band imaging in predicting colonoscopy surveillance intervals. Gastrointest Endosc. 2012;75(3): 494-502.

66. van den Broek FJC, Reitsma JB, Curvers WL, Fockens P, Dekker E. Systematic review of narrow-band imaging for the detection and differentiation of neoplastic and nonneoplastic lesions in the colon (with videos). Gastrointest Endosc. 2009;69(1):124-135.

67. Longcroft-Wheaton GR, Higgins B, Bhandari P. Flexible spectral imaging color enhancement and indigo carmine in neoplasia diagnosis during colonoscopy: a large prospective UK series. Eur J Gastroenterol Hepatol. 2011;23(10):903-911.

68. Pohl J, Nguyen-Tat M, Pech O, May A, Rabenstein T, Ell C. Computed virtual chromoendoscopy for classification of small colorectal lesions: a prospective comparative study. Am J Gastroenterol. 2008;103(3): $562-569$.

69. Sato R, Fujiya M, Watari J, et al. The diagnostic accuracy of highresolution endoscopy, autofluorescence imaging and narrow-band imaging for differentially diagnosing colon adenoma. Endoscopy. 2011;43(10):862-868 
70. Kuiper T, van den Broek FJC, Naber AH, et al. Endoscopic trimodal imaging detects colonic neoplasia as well as standard video endoscopy. Gastroenterology. 2011;140(7):1887-1894.

71. Ignjatovic A, East JE, Guenther T, et al. What is the most reliable imaging modality for small colonic polyp characterization? Study of white-light, autofluorescence, and narrow-band imaging. Endoscopy. 2011;43(2):94-99.

72. Rastogi A, Rao DS, Gupta N, et al. Impact of a computer-based teaching module on characterization of diminutive colon polyps by using narrowband imaging by non-experts in academic and community practice: a video-based study. Gastrointest Endosc. 2014;79(3):390-398.

73. Dik VK, Moons LM, Siersema PD. Endoscopic innovations to increase the adenoma detection rate during colonoscopy. World J Gastroenterol. 2014;20(9):2200-2211.

74. Baumann UA. Water intubation of the sigmoid colon: water instillation speeds up left-sided colonoscopy. Endoscopy. 1999;31(4):314-317.

75. Church JM. Warm water irrigation for dealing with spasm during colonoscopy: simple, inexpensive, and effective. Gastrointest Endosc. 2002;56(5):672-674.

76. Leung FW, Amato A, Ell C, et al. Water-aided colonoscopy: a systematic review. Gastrointest Endosc. 2012;76(3):657-666.

77. Rabenstein T, Radaelli F, Zolk O. Warm water infusion colonoscopy: a review and meta-analysis. Endoscopy. 2012;44(10):940-951.

78. Ansell J, Arnaoutakis K, Goddard S, et al. The WIMAT colonoscopy suitcase model: a novel porcine polypectomy trainer. Colorectal Dis. 2013;15(2):217-223; discussion 223.

79. Yoshida N, Naito Y, Kugai M, et al. Efficacy of hyaluronic acid in endoscopic mucosal resection of colorectal tumors. J Gastroenterol Hepatol. 2011;26(2):286-291.

80. Fujishiro M, Yahagi N, Kashimura K, et al. Different mixtures of sodium hyaluronate and their ability to create submucosal fluid cushions for endoscopic mucosal resection. Endoscopy. 2004;36(7): 584-589.
81. Yoshida N, Naito Y, Inada Y, et al. Endoscopic mucosal resection with $0.13 \%$ hyaluronic acid solution for colorectal polyps less than $20 \mathrm{~mm}$ : a randomized controlled trial. J Gastroenterol Hepatol. 2012; 27(8):1377-1383.

82. ASGE Technology Committee, Kantsevoy SV, Adler DG, et al. Endoscopic mucosal resection and endoscopic submucosal dissection. Gastrointest Endosc. 2008;68(1):11-18.

83. Yoshida N, Yagi N, Inada Y, et al. Possibility of ex vivo animal training model for colorectal endoscopic submucosal dissection. Int J Colorectal Dis. 2013;28(1):49-56.

84. Uraoka T, Parra-Blanco A, Yahagi N. Colorectal endoscopic submucosal dissection: is it suitable in western countries? J Gastroenterol Hepatol. 2013;28(3):406-414.

85. Ohata K, Ito T, Chiba H, Tsuji Y, Matsuhashi N. Effective training system in colorectal endoscopic submucosal dissection. Dig Endosc. 2012;24(Suppl 1):84-89.

86. Tanimoto MA, Torres-Villalobos G, Fujita R, et al. Endoscopic submucosal dissection in dogs in a World Gastroenterology Organisation training center. World J Gastroenterol. 2010;16(14):1759-1764.

87. Hon SSF, Ng SSM, Lee JFY, Li JCM, Lo AWI. In vitro porcine training model for colonic endoscopic submucosal dissection: an inexpensive and safe way to acquire a complex endoscopic technique. Surg Endosc. 2010;24(10):2439-2443.

88. Gotoda T, Friedland S, Hamanaka H, Soetikno R. A learning curve for advanced endoscopic resection. Gastrointest Endosc. 2005;62(6):866-867.

89. Choi IJ, Kim CG, Chang HJ, Kim SG, Kook M-C, Bae J-M. The learning curve for EMR with circumferential mucosal incision in treating intramucosal gastric neoplasm. Gastrointest Endosc. 2005; 62(6):860-865.
Advances in Medical Education and Practice

\section{Publish your work in this journal}

Advances in Medical Education and Practice is an international, peerreviewed, open access journal that aims to present and publish research on Medical Education covering medical, dental, nursing and allied health care professional education. The journal covers undergraduate education, postgraduate training and continuing medical education

\section{Dovepress}

including emerging trends and innovative models linking education, research, and health care services. The manuscript management system is completely online and includes a very quick and fair peer-review system. Visit http://www.dovepress.com/testimonials.php to read real quotes from published authors. 